\title{
Reaching youth at the point of sale: cigarette marketing is more prevalent in stores where adolescents shop frequently
}

\author{
L Henriksen, E C Feighery, N C Schleicher, H H Haladjian, S P Fortmann
}

Tobacco Control 2004;13:315-318. doi: 10.1136/tc.2003.006577

See end of article for authors' affiliations

....................

Correspondence to: Lisa Henriksen,

$\mathrm{PhD}$, Stanford Prevention

Research Center, 211

Quarry Road, N145,

Stanford, CA 94305-

5705;

lhenriksen@stanford.edu

Received

3 November 2003

Accepted 23 May 2004

\begin{abstract}
Objective: Although numerous studies describe the quantity and nature of tobacco marketing in stores, fewer studies examine the industry's attempts to reach youth at the point of sale. This study examines whether cigarette marketing is more prevalent in stores where adolescents shop frequently.

Design, setting, and participants: Trained coders counted cigarette ads, products, and other marketing materials in a census of stores that sell tobacco in Tracy, California $(n=50)$. A combination of data from focus groups and in-class surveys of middle school students $(n=2125)$ determined which of the stores adolescents visited most frequently.

Main outcome measures: Amount of marketing materials and shelf space measured separately for the three cigarette brands most popular with adolescent smokers and for other brands combined.

Results: Compared to other stores in the same community, stores where adolescents shopped frequently contained almost three times more marketing materials for Marlboro, Camel, and Newport, and significantly more shelf space devoted to these brands.

Conclusions: Regardless of whether tobacco companies intentionally target youth at the point of sale, these findings underscore the importance of strategies to reduce the quantity and impact of cigarette marketing materials in this venue.
\end{abstract}

S ince the Master Settlement Agreement (MSA), concern about tobacco marketing targeting youth has focused on

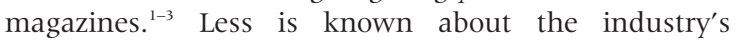
attempt to reach youth at the point of sale. In 2001, US cigarette companies spent $\$ 173$ million on magazine advertising compared to $\$ 9.5$ billion on retail marketing. ${ }^{4}$ These expenditures pay for traditional signs and functional items (such as branded clocks, hand baskets, and counter mats), price reductions for consumers ("Buy two, get one free") and incentives for retailers to display cigarettes in prime locations, especially around the counter. ${ }^{5}$ A US survey of approximately 3000 stores in 163 school neighbourhoods found some form of tobacco advertising at $84 \%$ of stores and at least one branded functional item in $69 \% .{ }^{6}$ The amount of money US tobacco companies spend on retail marketing has more than doubled since the 1998 MSA. $^{4}$ One effect of this spending has been observed in California's stores, where the average number of cigarette marketing materials increased $31 \%$ from 2000 to 2002 . $^{7}$

With a preponderance of tobacco ads and products located near candy and around the counter area, ${ }^{8-10}$ it stands to reason that retail tobacco marketing makes a clear impression on young consumers. In a survey of teens from northeast England, all of the 62915 and 16 year olds reported seeing point-of-purchase marketing for cigarettes. ${ }^{11}$ In the USA, adolescents who reported at least weekly exposure to retail tobacco marketing were more likely to have experimented with smoking, ${ }^{12}{ }^{13}$ and teen smokers preferred whichever brand (Camel or Marlboro) was advertised most heavily in the convenience store closest to school. ${ }^{14}$

The problem of widespread ads and promotions for cigarettes is not unique to US stores. ${ }^{15-18}$ For example, after countries such as Australia, Canada, Ireland, and New Zealand banned point-of-sale ads for cigarettes, traditional signs were replaced by "power walls" of cigarette packs in quantities greater than necessary to supply consumers. ${ }^{19}$ Exposure to such displays may distort adolescents' perceptions about the availability, use, and popularity of cigarettes. ${ }^{20}$
Whether or not tobacco companies intentionally target adolescents at the point of sale, some studies suggest they may be disproportionately exposed to this form of cigarette marketing. In metropolitan settings such as Boston, Massachusetts and San Jose, California, significantly more cigarette advertising was found on store windows within 300 metres of schools than on stores farther away from school. ${ }^{8} 10$ Combining data from store observations and school based surveys, this study is the first to examine whether cigarette marketing materials are more prevalent in stores where adolescents frequently shop.

\section{METHODS}

In February, 2002, observations were conducted in a census of stores that sold cigarettes in Tracy, California-a central valley community (population 62 500) approximately $100 \mathrm{~km}$ east of San Francisco. In 2000, the Tracy population was 65\% white, 8\% Asian, 6\% African American, 1\% American Indian, $20 \%$ other or multiple categories, and $28 \%$ of all residents were of Hispanic origin-quite comparable to the state population..$^{21}$ An address list for all Tracy businesses that paid tobacco taxes was obtained from the California Tobacco Control Section and verified with telephone directories and neighbourhood canvassing. Two tobacco-only stores that neither sold snack foods nor permitted entrance to youth under 18 were excluded from the store population, yielding a total of 50 stores.

Two young adults with substantial experience conducting observations of retail marketing were trained to use an established protocol for counting and categorising tobacco marketing materials in stores. ${ }^{22}$ Given concern about the role of cigarette packaging as a vehicle for advertising, ${ }^{23}{ }^{24}$ the protocol was expanded to measure shelf space allocated to cigarettes, as well. Branded signs, shelving units, product

Abbreviations: FCTC, Framework Convention on Tobacco Control; ICC, intraclass correlation coefficient; MSA, Master Settlement Agreement; STORE, Survey of Teen Opinions about Retail Environments 
displays, and functional items such as counter mats and shopping baskets were counted separately for the three cigarette brands most popular with youth in the USA (Marlboro, Camel, and Newport) ${ }^{25}$ and for other cigarette brands combined. Shelf space for cigarettes was measured by counting product facings, defined as space allocated to cigarette packs on the front row of shelves and displays. ${ }^{26}$ Cigarette cartons stacked with the longest side facing front were counted as five; cartons stacked with the shortest side facing front were counted as two.

For comparison, coders also counted branded signs, shelving units, product displays, and functional items for three of the most heavily advertised beer brands in the USA (Budweiser, Miller, and Heineken). ${ }^{27}$ Marketing materials for other beer brands were not counted because the sheer volume made it impossible for coders to complete the protocol in a reasonable amount of time.

Coders counted signs indicating that identification is required to purchase tobacco products that are supplied by the tobacco industry, such as the "We Card" sign from Philip Morris. Coders also rated the visual impact of cigarette advertising inside and outside each store using a four point scale adapted from Wakefield and colleagues. ${ }^{28}$ The scale values ranged from $0=$ no advertising to $3=$ everywhere/ "in your face". Store observations were completed before determining which stores were popular among adolescents, thus, the coders were blind to the assignment of stores to this category.

Stores were categorised by type: convenience, drug store/ pharmacy, grocery/deli, liquor, supermarket. ${ }^{22}$ Retail and/or gross square footage was not available from the County Tax Assessor's Office for all stores in the sample. Instead, cash register total was used as a proxy for store size because it was highly correlated with gross square footage in the stores where this figure was available $(\mathrm{n}=39, r=0.98$, $\mathrm{p}<0.001)$.

Only two of the 50 stores (4\%) refused a coder's request to spend 20 minutes counting and categorising signs for a study about point-of-purchase advertising. Six randomly selected stores were observed by the two coders independently and intercoder reliability for all measures was excellent. The highest intraclass correlation coefficients (ICCs) were obtained for counting cash registers (1.0) and age-of-sale signs (0.97), and for rating the visual impact of advertising (0.96); lower intercoder reliability was obtained for counting youth brand marketing materials and product facings (ICCs were 0.86 and 0.74 , respectively).

To determine which of the 48 stores were popular with teens, focus groups were conducted with one class from each of the three middle schools in Tracy. Students were asked to nominate 12 stores from the list of all retail tobacco outlets in the school catchment area (the area from which each school drew its student population). Some of the same stores were nominated at different schools, resulting in a total of 27 stores. The selections were confirmed by data from the Survey of Teen Opinions about Retail Environments (STORE) study-an in-class survey of 2125 students in grades 6-8 (ages 11-14 years) whose sample and procedures are described elsewhere. ${ }^{12}$ Each school's survey depicted photographs and addresses of the 12 nominated stores and measured the frequency with which students visited each store in the past month. More than one third of students $(38 \%)$ visited at least one of the 12 stores every day, $28 \%$ visited at least one of the 12 stores 2-3 times per week, and $14 \%$ visited at least one of the 12 stores weekly. Two of the 27 stores that the focus groups identified as popular were reclassified because more than $80 \%$ of surveyed students reported never shopping there.
Independent-sample $t$ tests compared the quantity of marketing materials and shelf space for cigarettes and the visual impact of cigarette advertising in stores popular with teens and other stores in the same community. The quantity of marketing materials and shelf space for "youth brands" (Marlboro, Camel, Newport) and other brands were also compared between the two groups of stores. To adjust for varying store size, such counts are typically divided by the number of cash registers. ${ }^{28}$ We report unadjusted means because the average size of stores popular among teens and other stores was not significantly different $(p=0.63)$, the unadjusted numbers are easier to interpret, and the conclusions from tests of adjusted and unadjusted means were essentially the same. Given the skewed distribution of some measures, we also conducted Mann-Whitney U tests, but results did not differ from the parametric tests reported.

\section{RESULTS}

The 48 stores contained an average (SD) of 22.6 (21.5) branded cigarette marketing materials and 123.8 (98.9) product facings per store. In the stores popular among adolescents, these numbers increased to 31.0 (24.5) and 153.1 (102.3) per store, respectively (table 1). Combining all brand impressions from marketing materials and products, adolescents were exposed to an average of 184.1 (109.2) cigarette brand impressions per store visit.

There were 3.4 times as many ads for cigarettes on windows of stores popular among adolescents than on other stores in the same community (table 1). Coders' impressions of the quantity of cigarette marketing materials confirmed a disparity between the two groups of stores, as well. Cigarette advertising had significantly greater visual impact in the popular than in the other stores (table 1).

The three brands most popular with adolescents (Marlboro, Camel, and Newport) accounted for $45 \%$ of all cigarette marketing materials and $45 \%$ of all shelf space for cigarettes in the 48 stores. Stores popular among adolescents contained almost three times more marketing materials and twice as much shelf space for Marlboro, Camel, and Newport than other stores in the same community (table 2). One possible explanation for this difference is that stores popular among adolescents were more likely to be the types of stores (convenience, liquor, and small grocery stores) which typically contain the most tobacco marketing. ${ }^{622}$ However, a $\chi^{2}$ test yielded no significant difference in the distribution of store types between the popular and other stores.

Another plausible explanation is that stores popular among adolescents were also popular among adults and therefore contain more advertising for the top selling brands (Marlboro, Camel, and Newport) and more advertising overall. However, we found no differences between popular and other stores in the quantity of marketing materials and

Table 1 Mean (SD) number of cigarette marketing materials and their visual impact by store popularity (Tracy, California)

\begin{tabular}{|c|c|c|c|}
\hline & \multicolumn{2}{|c|}{$\begin{array}{l}\text { Stores popular among } \\
\text { youth }\end{array}$} & \multirow[b]{2}{*}{$\mathrm{p}$ Value } \\
\hline & No $(n=24)$ & Yes $(n=24)$ & \\
\hline \multicolumn{4}{|l|}{ Marketing materials by location } \\
\hline Exterior* mean (SD) & $1.7(2.6)$ & $5.8(6.4)$ & 0.03 \\
\hline Interior* & $12.6(13.5)$ & $25.2(23.6)$ & 0.12 \\
\hline Shelf space (facings)* & $94.4(87.8)$ & $153.1(102.3)$ & 0.16 \\
\hline Overall visual impact $(0-3) \dagger$ & $0.9(0.6)$ & $1.4(0.7)$ & 0.01 \\
\hline
\end{tabular}


Table 2 Mean (SD) quantity of cigarette marketing materials and shelf space by brand and store popularity (Tracy, California)

\begin{tabular}{|c|c|c|c|}
\hline & \multicolumn{2}{|c|}{$\begin{array}{l}\text { Stores popular among } \\
\text { youth }\end{array}$} & \multirow[b]{2}{*}{$\mathrm{p}$ Value } \\
\hline & No $(n=24)$ & Yes $(n=24)$ & \\
\hline \multicolumn{4}{|c|}{ Cigarette marketing materials } \\
\hline Youth brands & $5.3(5.8)$ & $14.8(11.4)$ & 0.01 \\
\hline Other brands & $9.0(9.5)$ & $16.1(14.1)$ & 0.15 \\
\hline \multicolumn{4}{|c|}{ Cigarette shelf space (facings) } \\
\hline Youth brands & $36.3(36.7)$ & $75.5(53.4)$ & 0.02 \\
\hline Other brands & $58.1(55.2)$ & $77.6(54.5)$ & 0.60 \\
\hline $\begin{array}{l}{ }^{*} f \text { Tests compar } \\
\text { unadjusted. }\end{array}$ & for store si & ze; cell mear & \\
\hline
\end{tabular}

shelf space for cigarette brands other than Marlboro, Camel, and Newport (table 1). Nor did we find a significant difference between the quantity of marketing materials for three top selling beer brands (Budweiser, Miller, and Heineken) in stores popular among adolescents (mean (SD) $25.5(25.0))$ and the other stores (23.5 (24.2)).

Finally, we tested whether the tobacco industry's signs about identification required for tobacco purchase were more numerous in the stores popular among teens than in the other stores. California law requires a sign at every cash register warning against illegal tobacco sales to minors, but no law governs the number or placement of such warnings provided to retailers by the tobacco industry. Ironically, stores popular among teens displayed more of the industry's signs and shelving to promote Marlboro, Camel, and Newport, but did not display more of the industry's signs to discourage minors from purchasing these products illegally (mean (SD) $3.9(2.4))$ than did other stores $(3.7(3.2))$.

\section{DISCUSSION}

According to this study, cigarettes are marketed more heavily in stores where adolescents shop-particularly the cigarette brands most popular with adolescent smokers. Compared to other stores in the same community, stores popular among adolescents displayed more than three times as many cigarette marketing materials outside, and contained almost three times more marketing materials and twice as much shelf space for Marlboro, Camel, and Newport. These three brands account for more than $80 \%$ of the cigarettes bought by US adolescents. ${ }^{29}$ The four brands advertised most heavily in US stores (Marlboro, Camel, Winston, and Newport) ${ }^{30}$ are three of the four brands with the largest sales revenue (Marlboro, Newport, Doral, Camel). ${ }^{31}$ The relation between market share and the prevalence of marketing materials and product facings in stores warrants further research, particularly since advertising is related more strongly to cigarette brand choice among adolescents than adults. ${ }^{32}$

This study is the first we are aware of to measure shelf space for cigarettes as an indicator of retail tobacco marketing. The fact that Marlboro, Camel, and Newport accounted for $45 \%$ of all marketing materials and $45 \%$ of all shelf space for cigarettes in the 48 stores may be purely coincidental. It may also suggest that tobacco companies consider self space devoted to their brands as important as other forms of instore marketing.

\section{Study limitations}

The school based survey did not assess the frequency with which adolescents visited all retail tobacco outlets in the school catchment area. Thus, we cannot confirm that unpopular stores were visited less frequently than the stores nominated by the focus groups. However, incorrect

\section{What this paper adds}

Two previous studies found more cigarette ads on store windows within 300 metres of schools than on stores farther away from school, but lacked information about where adolescents shop. This study combined school based surveys with retail observations to determine whether cigarettes are promoted more heavily in stores where adolescents shop frequently. Such stores contained more marketing materials and shelf space for Marlboro, Camel, and Newport than did other stores in the same community. Simply eliminating ads may be insufficient to substantially reduce adolescents' exposure to cigarette brand impressions in stores because the preponderance of these come from product displays. Future restrictions on retail tobacco marketing should consider the potential impact of cigarette packaging as well as advertising.

classification would likely decrease the observed differences between the two groups of stores. Future research should use other means to determine which stores are most popular with adolescents, such as merchant interviews or consumer marketing data.

The current study classified marketing materials and product facings into only four brand categories-Marlboro, Camel, Newport, or other. Although "other brands" is a potentially crude comparison for "youth brands", it is unlikely that one or two brand names accounted for most of the marketing materials recorded in the "other" category. In a survey of 1565 US stores, Marlboro, Camel, and Newport accounted for $46 \%$ of all cigarette marketing materials, seven of the remaining top 10 brands accounted for $42 \%$, and innumerable other brands accounted for the remaining $12 \% .^{33}$ The absence of reliable information about the total number of cigarette brands advertised in stores makes it difficult to appreciate the extent to which brands favoured by teen smokers dominate the retail environment. Indeed, it would be helpful if the Federal Trade Commission or other organisations maintained a list of cigarette brands sold.

Although this study examined a small sample of stores in a single California community, observations about the quantity of cigarette marketing materials are quite similar to those from larger, more representative samples. For example, the average number of cigarette marketing materials was slightly lower than the average for a California sample of 569 stores (22.7 $v$ 25, respectively), ${ }^{7}$ and the proportion of marketing materials for Marlboro, Camel, and Newport in this sample was comparable to the California sample ${ }^{7}$ and to a US sample of 1565 stores $\left(45 \%, 42 \%\right.$, and $46 \%$, respectively). ${ }^{30}$ Using a standardised protocol to quantify marketing materials and shelf space for cigarettes, future research should compare the quantity of marketing materials in countries with varying regulations at the point of sale, and determine whether adolescents are disproportionately exposed to cigarette marketing materials, particularly to brands favoured by young smokers.

\section{Implications for tobacco control}

Several examples serve to illustrate how successfully US tobacco companies have avoided restrictions on advertising at the point of sale. The MSA, which bans cigarette ads on billboards and limits such ads in magazines and at sponsored events, contains only two provisions that affect ads in stores. ${ }^{34}$ One provision limits the size of exterior ads to 14 square feet and another prohibits using cartoons to advertise cigarettes in stores or elsewhere. More stringent regulations proposed by the US Food and Drug Administration-mandating 
black-and-white, text only advertisements and banning self service displays - did not survive judicial review. ${ }^{35}$ The US Supreme Court also struck down a Massachusetts law that prohibited placing cigarette ads within 5 feet of the store floor-at children's eye level. ${ }^{36}$

The Framework Convention on Tobacco Control (FCTC) does not specify point of sale in its recommendation to ban tobacco advertising, promotion, and sponsorship. ${ }^{37}$ However, the FCTC endorses larger, more vivid warning labels on cigarette packs, like those in Canada and Brazil, which are clearly visible in stores and may serve as important cues to reduce tobacco use. ${ }^{38}$ Countries such as Ireland, New Zealand, and Thailand, and several Canadian provinces and Australian states reduce young people's exposure to tobacco marketing by banning tobacco ads at the point of sale. Requiring merchants to stock cigarette packs out of sight, in overhead bins or beneath the counter, is also recommended to prevent smoking. ${ }^{39}$ According to this study, that practice could reduce US adolescents' exposure to cigarette brand impressions in stores by as much as $83 \%$.

This study is unique in pairing adolescent self reports with in-store observations to demonstrate that stores popular among adolescents contain more marketing materials and shelf space for Marlboro, Camel, and Newport than other stores in the same community. A replication with larger samples in other jurisdictions is clearly warranted to determine whether this is a pervasive pattern or isolated incident. Whether tobacco companies intentionally target youth at the point of sale also warrants further investigation. Indeed, the strategic use of this venue to reach youth would not be surprising in environments that increasingly restrict tobacco companies' access to traditional advertising venues, such as billboards, magazines, and other media. At a time when cigarette packaging is an increasingly important component of tobacco marketing, ${ }^{24}{ }^{40} 41$ this study underscores the need for strategies that would reduce the quantity and impact of adolescents' exposure to cigarette brand impressions in stores.

\section{ACKNOWLEDGEMENTS}

This study was funded by Public Health Service grant CA67850 from the National Cancer Institute.

\section{Authors' affiliations}

L Henriksen, E C Feighery, N C Schleicher, H H Haladjian, S P Fortmann, Stanford University School of Medicine, Stanford Prevention Research Center, Stanford, California, USA

\section{REFERENCES}

1 Chung PJ, Garfield CF, Rathouz PJ, et al. Youth targeting by tobacco manufacturers since the Master Settlement Agreement. The first study to document violations of the youth-targeting ban in magazine ads by the three top U.S. tobacco companies. Health Aff (Millwood) 2002;21:254-63.

2 Hamilton WL, Turner-Bowker DM, Celebucki CC, et al. Cigarette advertising in magazines: The tobacco industry response to the Master Settlement Agreement and to public pressure. Tobacco Control 2002;11(suppl II):ii54-8.

3 King C III, Siegel M. The Master Settlement Agreement with the tobacco industry and cigarette advertising in magazines. N Engl J Med 2001;345:504-11.

4 Federal Trade Commission. Report to Congress for 2001 pursuant to the Federal Cigarette Labeling and Advertising Act. Washington DC: US Federal Trade Commission, 2003.

5 Feighery EC, Ribisl KM, Clark PI, et al. How tobacco companies ensure prime placement of their advertising and products in stores: interviews with retailers about tobacco company incentive programmes. Prev Med 2003;12:184-8.

6 Centers for Disease Control and Prevention. Point-of-purchase tobacco environments and variation by store type - United States, 1999. MMWR Morb Mortal Wkly Rep 2002;51:184-9.

7 Feighery E, Cruz T. What's happening in California stores? Presented at the National Conference on Tobacco or Health, Boston, Massachusetts, December, 2003.
8 Pucci LG, Joseph HM Jr, Siegel M. Outdoor tobacco advertising in six Boston neighborhoods: evaluating youth exposure, Am J Prev Med 1998;15:155-9.

9 Roeseler A, Russell C, Rogers T, et al. Operation Storefront: youth against tobacco advertising and promotion. Phase I survey results. Sacramento: California Department of Health Services, 1995.

10 Rogers T, Feighery EC, Tencati E, et al. Community mobilization to reduce point-of-purchase advertising of tobacco products. Health Education Quarterly 1995;22:427-42.

11 MacFadyen L, Hastings G, MacKintosh AM. Cross sectional study of young people's awareness of and involvement with tobacco marketing. BMJ 2001;322:513-17.

12 Henriksen L, Feighery EC, Wang Y, et al. Association of retail tobacco marketing with adolescent smoking. Am J Public Health, (in press).

13 Schooler C, Feighery EC, Flora J. Seventh graders' self-reported exposure to cigarette marketing and its relationship to their smoking behavior. Am J Public Health 1996;86:1216-21.

14 Wakefield MA, Ruel EE, Chaloupka FJ, et al. Association of point-of-purchase tobacco advertising and promotions with choice of usual brand among teenage smokers. Journal of Health Communication 2002:7:1 13-21.

15 Carter SM. Going below the line: creating transportable brands for Australia's dark market. Tobacco Control 2003;12(suppl III):iii87-94.

16 Carter SM. New frontier, new power: the retail environment in Australia's dark market. Tobacco Control 2003;12(suppl III):iii95-101.

17 Anderson S, Hastings G, MacFadyen L. Strategic marketing in the UK tobacco industry. Lancet Oncol 2002;3:481-6.

18 Ciecierski CU, Campbell S, MacKintosh AM. A closer look at marketing at the point of sale: results from Poland. Presented at the National Conference on Tobacco or Health, Boston, Massachusetts, December, 2003.

19 Greaves L. Canada: demolishing the power walls. Tobacco Control 2003;12:7-8.

20 Henriksen L, Flora JA, Feighery EC, et al. Effects on youth of exposure to retail tobacco advertising. J Applied Soc Psychol 2002;32:1771-89.

21 US Census Bureau. American Fact Finder - People. 2000. Available at: http://factfinder.census.gov/home/saff/main.html[Accessed Aug 25, 2003].

22 Feighery EC, Ribisl KM, Schleicher N, et al. Cigarette advertising and promotional strategies in retail outlets: results of a statewide survey in California. Tobacco Control 2001;10:184-8.

23 Slade J. The pack as advertisement. Tobacco Control 1997;6:169-70.

24 Wakefield MA, Morley C, Horan JK, et al. The cigarette pack as image: new evidence from tobacco industry documents. Tobacco Control 2002;11(suppl I): i73-80.

25 Substance Abuse and Mental Health Services Administration. Results from the 2002 National Survey on Drug Use and Health: national findings, (Office of Applied Studies, NHSDA Series H-22, DHHS Publication No. SMA 033836). Rockville, Maryland, 2003.

26 Point-of-Purchase Advertising Institute. P-O-P advertising desktop reference guide. Washington DC: Point-of-Purchase Advertising Institute, 1999.

27 Center on Alcohol Marketing and Youth. Television: Alcohol's vast adland. 2002. Available at: hittp://camy.org/research/files/ television 1202.pdf[Accessed April 9, 2004].

28 Wakefield MA, Terry-McElrath YM, Chaloupka FJ, et al. Tobacco industry marketing at point of purchase after the 1998 MSA billboard advertising ban. Am J Public Health 2002;92:937-40.

29 Kaufman NJ, Castrucci BC, Mowery P, et al. Changes in adolescent cigarettebrand preference, 1989 to 1996. Am J Health Behav 2004;28:54-62.

30 Feighery EC, Ribisl KM, Schleicher NC, et al. Cigarette company marketing strategies in stores: results of a national survey. Tobacco Control (under review).

31 Beirne M. The cheap inherit the Earth? Brandweek, 2003 June 23, s61.

32 Pollay RW, Siddarth S, Siegel M, et al. The last straw? Cigarette advertising and realized market shares among youths and adults, 1979-1993. Journal of Marketing 1996;60:1-16.

33 Feighery EC, Ribisl KM, Schleicher NC, et al. Retailer participation in cigarette company incentive programs is related to increased levels of cigarette advertising and cheaper cigarette prices in stores. Prev Med 2004;38:876-84

34 National Association of Attorneys General (NAAG). Master Settlement Agreement: Proposed Settlement of State Cases; Section II(ii); 1998 December 8.

35 Food and Drug Administration. v. Brown \& Williamson Tobacco Corp, 153 F3d 155 ( $4^{\text {th }}$ Cir 2000)

36 Lorillard Tobacco Co. v. Reilly, 533 US 525 ( $1^{\text {st }}$ Cir 2001)

37 World Health Organization. WHO framework convention on tobacco control, 2003.Available at: http://www.who.int/tobacco/areas/framework/ final_text/en/[Accessed May, 2003].

38 Hammond D, Fong GT, McDonald PW, et al. Impact of the graphic Canadian warning labels on adult smoking behaviour. Tobacco Control 2003; 12:391-5.

39 Jamrozik K. Population strategies to prevent smoking. BMJ 2004;328:759-62.

40 Barnsley K, Jacobs M. Tobacco advertising and display of tobacco products at point of sale: Tasmania, Australia. Tobacco Control 2000;9:230-2.

41 Fraser T. Phasing out of point-of-sale tobacco advertising in New Zealand. Tobacco Control 1998;7:82-4. 